\title{
Effect of Urbanization on Child Safety
}

\author{
Hossein Kazemeini ${ }^{1}$, Alireza Moghisi' ${ }^{1}$, Aminda Amanolahi ${ }^{*}$, Hamed Barekati², \\ Shila Ghadami ${ }^{2}$ \\ ${ }^{1} \mathrm{PHC}$ center, Ministry of Health and Medical Education, Tehran, Iran \\ ${ }^{2}$ Family and Population Health Office, Ministry of Health and Medical Education, Tehran, Iran \\ Email: kazemeini2002@yahoo.com, alirezamoghisi@yahoo.com, \\ drbarekati@yahoo.com, shilaghadami@yahoo.com
}

Received 18 May 2015; accepted 14 July 2015; published 17 July 2015

Copyright (C) 2015 by authors and Scientific Research Publishing Inc.

This work is licensed under the Creative Commons Attribution International License (CC BY). http://creativecommons.org/licenses/by/4.0/

(c) () Open Access

\begin{abstract}
Background: The world's population living in urban areas has grown up from $14 \%$ to over $50 \%$. This study was designed aiming to compare injuries related mortality and morbidity in Urban vs Rural settings among children in Iran. Methods: Data were gathered from a household survey. A t-test was used to analyze the relationship between outcomes. Achievements: Injury in all ages accounts for $17 \%$ of all deaths in Iran. $20 \%$ of death in children is due to injuries. Children in urban settings sustain injuries due to traffic accident, airway blockage and fall from height more than rural children. About $63.5 \%$ of morbidity related to injuries occurs in private homes or in residential areas e.g. yards and compounds. In these injuries, no significant statistically difference was found between rural vs. urban setting ( $p \leq 0.05)$. Conclusion: Beside area level measures as an index for considering urbanization, other elements including quality of roads, distances from markets and so on should be considered as well. Safety for children is an important element to be provided prior to planning cities by urban developers. Expansion of the International Safe Community program is a potential solution.
\end{abstract}

\section{Keywords}

Urbanization, Child Safety, Injuries, Iran

\section{Introduction}

The process whereby a society changes from a rural to an urban way of life is called urbanization. The world's population living in urban areas has grown up from $14 \%$ to over $50 \%$. For the first time in history, more than $50 \%$ of the world's population lives in an urban area [1]. In a few short decades, all regions in the world will be predominantly urban. By 2030, six out of every 10 people will be city dwellers, rising to seven out of every 10

*Corresponding author. 
people by 2050 [1]. The World Health Organization chose the theme of "urbanization and health" for World Health Day, on 7 April 2010, in recognition of effect of urbanization has on our collective health globally and on every individual. Its goal was to draw worldwide attention to the theme of urbanization and health and to involve governments, international organizations, business and civil society in a shared effort to put health at the heart of urban policy "The world is rapidly urbanizing with significant changes in our living standards, lifestyles, social behavior and health,” says Dr Jacob Kumaresan, director of the World Health Organization's Centre for Health Development based in Kobe, Japan. "While urban living continues to offer many opportunities, including potential access to better health care, today's urban environments can concentrate health risks and introduce new hazards [1]. It is associated with many changes including greater access to transportation and clear implications for determining the disease and injury pattern. Health challenges particularly evident in cities relate to water, environment, violence and injury, non communicable diseases (cardiovascular diseases, cancers, diabetes and chronic respiratory diseases), unhealthy diets and physical inactivity, harmful use of alcohol as well as the risks associated with disease outbreaks. City living and its increased pressures of mass marketing, availability of unhealthy food choices and accessibility to automation and transport all have an effect on lifestyle that directly affects health [1].

Globally, road traffic injuries are the ninth leading cause of death, and most road traffic deaths occur in lowand middle-income countries [1].

Almost half of those who die in road traffic crashes are pedestrians, cyclists or users of motorized two-wheelers [1]. Urban environments tend to discourage physical activity and promote unhealthy food consumption. Participation in physical activity is made difficult by a variety of urban factors including overcrowding, high-volume traffic, and heavy use of motorized transportation, poor air quality and lack of safe public spaces and recreation/ sports facilities [1].

Iran has the most growing population located in urban and sub urban areas of big cities. In this context children are the most vulnerable group to be affected by the ongoing process of urbanization. This study was performed to estimate the effect of urbanization on child safety including road traffic accident. Islamic Republic of Iran, one of the developing countries in the EMRO region, is fast growing towards urbanization, about 2/3 of the 72,000,000 population live in urban areas, mostly in megacities including Tehran, Karaj, Isfahan, Shiraz, Tabriz and Mashhad. Here we review some of the health-related aspects of urbanization, and comment on strategies designed to improve urban health in Isfahan province [2].

This study was designed with aim to compare injuries related mortality in Urban and Rural settings in Iran.

\section{Methodology}

We constructed a measure of population size as one of the elements of urbanization using validated data from the national census of Iran 2006. For continuous exposure data of normal distribution, a T test was used to analyze the relationship between outcome variables from each of the urbanization groups.

\section{Results}

Mortality results in children based on sex and age is as follows: in age groups under 1, 1 - 4 and 5 - 9 years the most important cause of death was communicable diseases and mal formation followed by Non communicable disease and Injury, but in age groups 10 - 14 and 15 - 19 the most important cause of death was injuries.

In age group 1 - 4, the rate of deaths due to injuries and non-communicable diseases was the same 11 in 1000 live birth. The highest death rate and the lowest death rate due to Injury was revealed among age group 15 - 19 and under one year respectively, 53/1000 vs 2/1000 live births. By increasing age, injuries become more prominent as a main cause of death (Figure 1).

The most important cause of death among children under five years of age in Iran was congenital anomalies, Injuries and respiratory disorders. Injuries account for the second cause of death in this age group (Figure 2).

In all age groups the mortality rate from injuries remains high in male children except burn injury that is higher among female children than male individuals. Since girl children like to cook hence this group is more prone to burn. In urban setting Road traffic injuries is the first cause of death among the children followed by air obstruction. But in rural and suburban settings the first cause of death from injury remains unchanged but the second cause is due to drowning. Since in rural areas pools and pounds are unprotected and children in this age will not pay enough attention not to approach to these zones $(\mathrm{P}<0.05)$ (Figure 3).

Homes are supposed to be the safest place for everybody, people escapes from dangers to homes. Unfortunately 


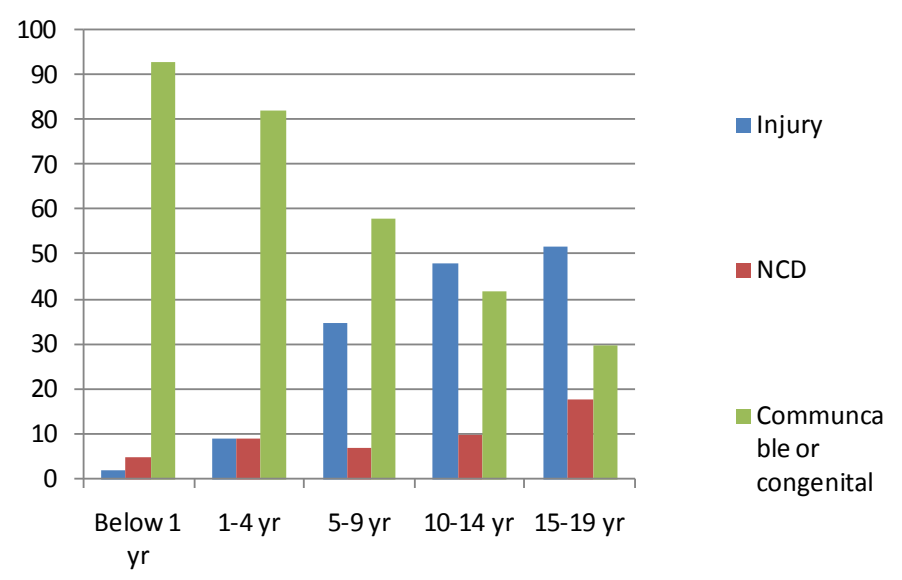

Figure 1. Child mortality rate in 1000 live births by age and cause.

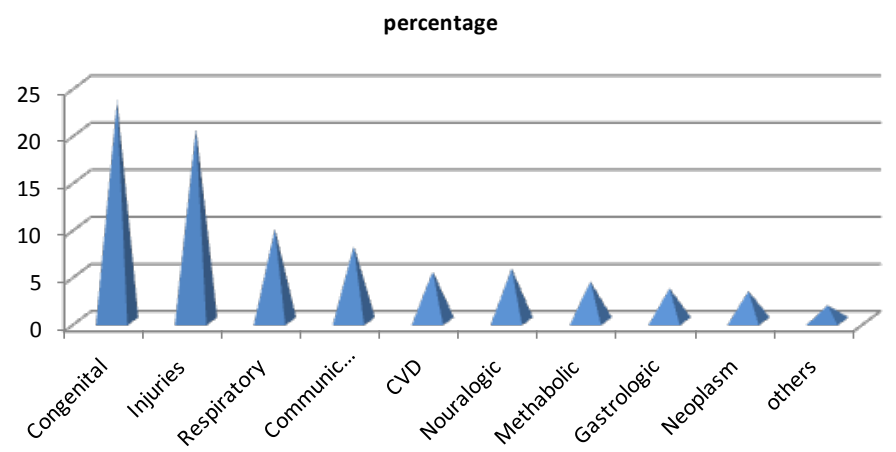

Figure 2. Causes of under 5 mortality in Iran.

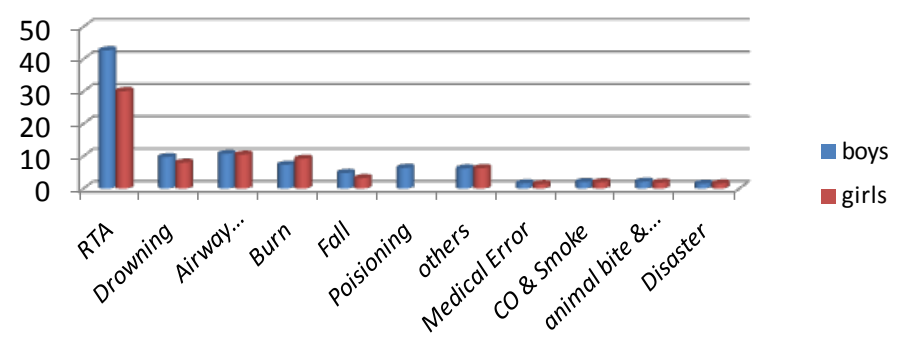

Figure 3. Child mortality by type of injury.

homes and home surroundings are the most common place to cause death and injuries to children in both settings, 62.5 percent of all death happened in home and home's surrounding (Figure 4). The second most common place of death related injuries in rural areas was home surroundings which accounts for $24 \%$ of all related death, but in urban area; this figure is $18 \%$ in urban areas. Roads in urban areas are responsible for $30 \%$ of place of death. In rural setting, the death rate in home and home surroundings was higher, $74 \%$ versus $52 \%$ (Figure 5). In Urban settings the death from road traffic accident was the highest. $42 \%$ of death related injuries take place on roads and streets of urban areas of Iran. This could be justified that roads in urban settings are predominant than in rural settings (Figure 6).

$16 \%, 10 \%, 8 \%$ and $3 \%$ of total deaths in rural areas is due to drowning, burn, fall and disaster respectively. These rates are higher in rural areas compare to urban settings $(P<0.05)$ (Figure 6). The highest death from injuries among children was revealed in Southernkhorasan, Western Azarbaiejan and Markazi provinces. Since 2007 till 2010 the first and second cause of death was due to road traffic accident (RTA) and drowning respectively $(\mathrm{P}<0.05)$. The lowest rate was due to animal bite $\&$ stings with a tiny change in pattern during these years. All deaths related injury has had a decreasing trend except RTA during 2007 to 2010 (Figure 7). 


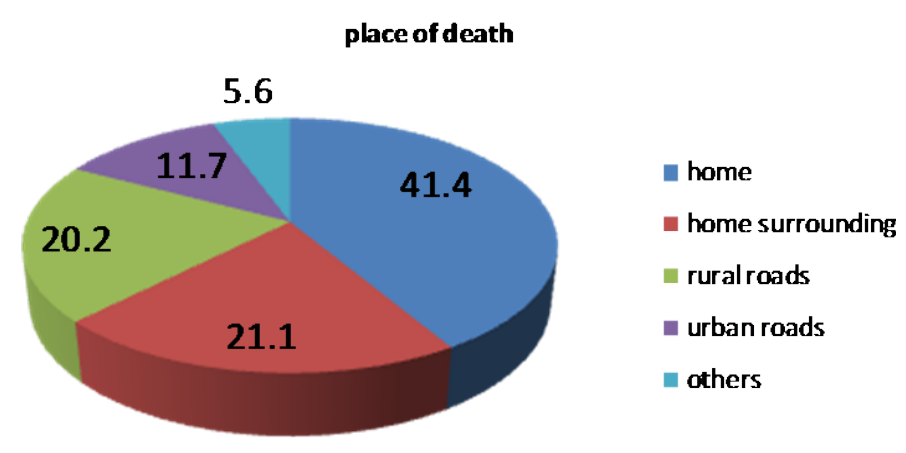

Figure 4. Place of death among children.

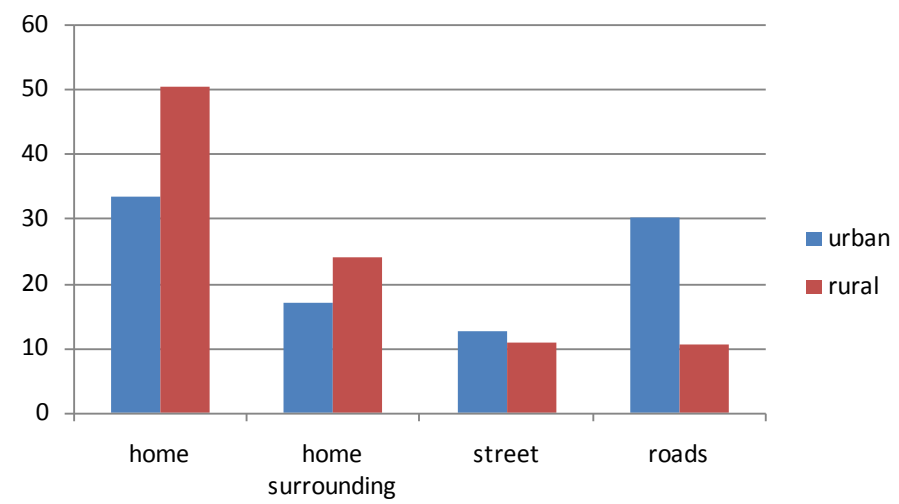

Figure 5. Child mortality by place of death and urbanization.

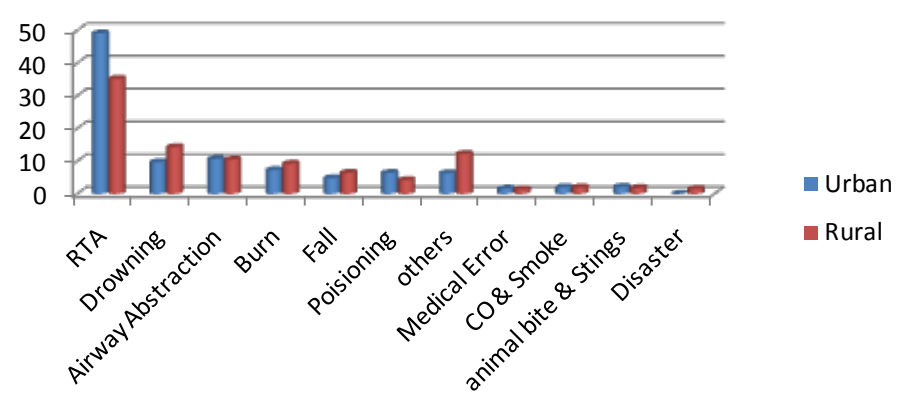

Figure 6. Child mortality by urbanization.

\section{Discussion}

Urban areas were reported to have high road traffic mortality in India [3] [4] and sustain more injuries in South East Iran [5] compared to rural areas.

In Nigeria, the difference in incidence of road traffic accident in the past 12 months between urban areas and rural areas was significant towards rural area [6]. While in China [7] [8], South Africa [9], and USA [10], Road traffic mortality rate was higher in rural areas compare to urban areas [11].

In a systematic review of total of 41 studies (7 surveys and 34 studies using administrative health database) with a moderate Internal validity, Rural children were at higher risk of overall injury, motor vehicle crash injury and suicide, whereas urban children in the USA experienced higher rates of firearm-related homicides [12].

In the Islamic Republic of Iran in a one year period from 2007 to 2008 traffic accidents has had the highest increase (5 percent). Place of unintentional injuries among the children age below 5 years old was $43 \%$ at home, $19.5 \%$ in residential surrounding, $9.6 \%$ in urban roads and 21.7 suburban roads. Place of injuries at home and home area were higher in rural settings, but on streets and roads were higher in urban areas [2].

Home related and traffic related deaths among children below 5 years of age were $43.9 \%$ and $11.2 \%$ respec- 


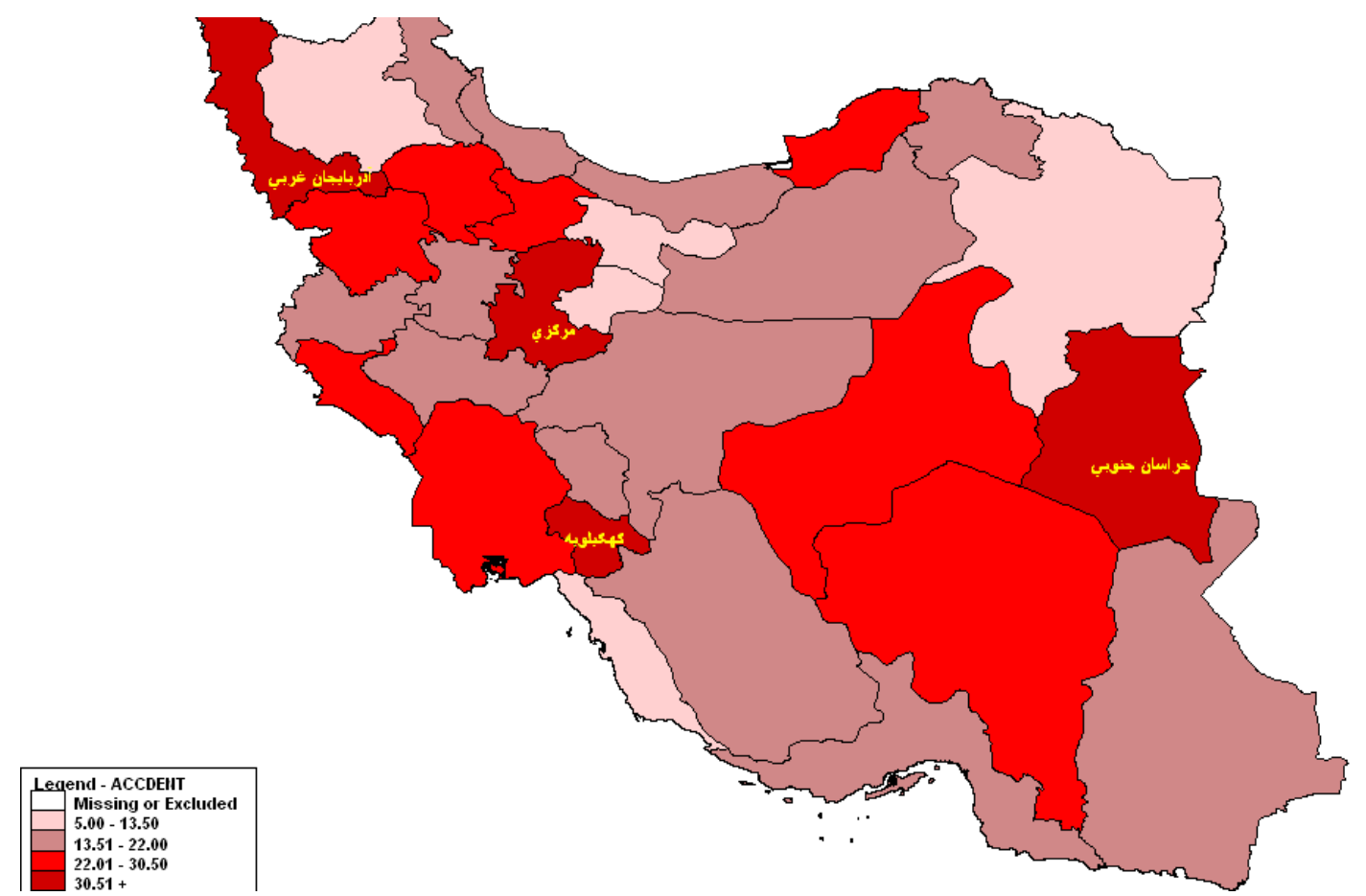

Figure 7. Disparity on child Injury related mortality.

tively. Both crude and age-adjusted injury death rates were higher in rural areas than in urban areas in Hubei Province (China) during 2006-2008 [13]. Residents of rural areas had an injury death rate twice that in urban areas. Similar findings had been reported elsewhere in China [7] [8] [14]. Other studies have also identified higher injury mortality rates in rural versus urban locations in most developing and developed countries [15]-[19]. The urban-rural discrepancy (30.1 vs 70.7 per 100,000) is wider than that of Tanzania (40.5 vs 48.5 per 100,000 in female, 108.8 vs 138.3 per 100,000 in male [12], Australia (33.2 vs 48.1 per 100,000) [11] and the United states (44.6 vs 31.2 per 100,000) [15]. External causes were the most common causes of death among Lithuanin children and adolescents aged up to 19 years, accounting for $36.5 \%$ of overall mortality during the period of 1988-2000 [20].

Considerable inequalities in mortality by sex, age, and place of residence were disclosed pointing out boys, children under one year of age, adolescents aged 15 - 19 years, and residents of rural areas as the most vulnerable groups most traffic crashes, for instance, occur in urban areas in both low and high-income countries. Globally 30\% - 70\% of traffic crashes occurs on roads in urban areas (World Bank, 2001) [20].

Urban areas were reported to have high road traffic mortality in India [3] [4] and sustain more injuries in South East Iran [5] compared rural areas.

In Nigeria, the difference in road traffic incidence in the past 12 months between urban areas and rural areas was insignificant [6]. While in China [7] [8], South Africa [9], and USA [10], rural areas were reported having higher road traffic mortality than urban areas. More deaths occur on rural roads than on urban ones. In 2010, there were 1046 fatal accidents on rural roads compared to over 572 on urban roads [11].

The number of deaths on rural roads has also decreased at a slower rate than deaths on urban roads. Overall, healthcare costs per child for injury were higher for rural children but that risk is far outweighed by the fact that you're about twice as likely to die in a car crash in rural America as you are in the most urban counties.

\section{Conclusions}

Male children in urban and rural areas are suffered from injury related deaths disproportionally than females individual. In all age groups the mortality rate from injuries remains high in male children except burn injury that is higher among female children. By increasing age, injuries become more prominent as a main cause of death, then it is necessary to educate these age groups like students in the school. Urbanization has a reverse impact on child's safety and health in terms of road traffic accident, but has protective effect on home's related deaths. 
Civil planners should consider safety of children on roads and streets while designing cities.

The results show that there is disparity on child injury related mortality between different provinces in the country, then a study should be performed to find the reason for this difference and consider the proper intervention and policy.

\section{References}

[1] Campbell-Lendrum, D. and Bertollini, R. (2010) Urbanization and Health. Bulletin of the World Health Organization, Past Issues, 88, 241-320.

[2] Rahbar, M., Ahmadi, M., Lornejad, H.R., Habibelahi, A., Sanaei-shoar, T. and Mesdaghinia, A.R. (2013) Death Surveillance for Children 1 - 59 Months in Iran 2008. Iranian Journal of Public Health, 42, 93-97.

[3] Hsiao, M., Malhotra, A., Thakur, J.S., Sheth, J.K., Nathens, A.B., Dhingra, N. and Jha, P. (2013) Million Death Study Collaborators: Road Traffic Injury Mortality and Its Mechanisms in India: Nationally Representative Mortality Survey of 1.1 Million Homes. BMJ Open, 3, e002621.

[4] Jagnoor, J., Suraweera, W., Keay, L., Ivers, R.Q., Thakur, J. and Jha, P. (2012) Million Death Study Collaborators: Unintentional Injury Mortality in India, 2005: Nationally Representative Mortality Survey of 1.1 Million Homes. BMC Public Health, 12, 487. http://dx.doi.org/10.1186/1471-2458-12-487

[5] Ansari-Moghaddam, A., Martiniuk, A.L., Mohammadi, M., Rad, M., Sargazi, F., Sheykhzadeh, K., Jelodarzadeh, S. and Karimzadeh, F. (2012) The Pattern of Injury and Poisoning in South East Iran. BMC International Health and Human Rights, 12, 17. http://dx.doi.org/10.1186/1472-698X-12-17

[6] Labinjo, M., Juillard, C., Kobusingye, O.C. and Hyder, A.A. (2009) The Burden of Road Traffic Injuries in Nigeria: Results of a Population-Based Survey. Injury Prevention, 15, 157-162. http://dx.doi.org/10.1136/ip.2008.020255

[7] Hu, G., Baker, S.P. and Baker, T.D. (2010) Urban-Rural Disparities in Injury Mortality in China. The Journal of Rural Health, 26, 73-77. http://dx.doi.org/10.1111/j.1748-0361.2009.00255.X

[8] Wang, S.Y., Li, Y.H., Chi, G.B., Xiao, S.Y., Ozanne-Smith, J., Stevenson, M. and Phillips, M.R. (2008) Injury-Related Fatalities in China: An Under-Recognised Public-Health Problem. The Lancet, 372, 1765-1773. http://dx.doi.org/10.1016/S0140-6736(08)61367-7

[9] Olukoga, A. and Harris, G. (2006) Field Data: Distributions and Costs of Road-Traffic Fatalities in South Africa. Traffic Injury Prevention, 7, 400-402. http://dx.doi.org/10.1080/15389580600847560

[10] Goldstein, G.P., Clark, D.E., Travis, L.L. and Haskins, A.E. (2011) Explaining Regional Disparities in Traffic Mortality by Decomposing Conditional Probabilities. Injury Prevention, 17, 84-90. http://dx.doi.org/10.1136/ip.2010.029249

[11] Huang, Y.X., Tian, D.P., Gao, L., Li, L., Deng, X., Mamady, K. and Hu, G.Q. (2013) Neglected Increases in Rural Road Traffic Mortality in China: Findings Based on Health Data from 2005 to 2010. BMC Public Health, 13, 1111. http://dx.doi.org/10.1186/1471-2458-13-1111

[12] Kim, K., Ozegovic, D. and Voaklander, D.C. (2012) Differences in Incidence of Injury between Rural and Urban Children in Canada and the USA: A Systematic Review. Injury Prevention, 18, 264-271. http://dx.doi.org/10.1136/injuryprev-2011-040306

[13] Liu, Q., Zhang, L., Li, J.L., Zuo, D., Kong, D.G., Shen, X.F., Guo, Y. and Zhang, Q.J. (2012) The Gap in Injury Mortality Rates between Urban and Rural Residents of Hubei Province, China. BMC Public Health, 12, 180. http://dx.doi.org/10.1136/injuryprev-2011-040306

[14] Jiang, G., Choi, B.C., Wang, D., Zhang, H., Zheng, W., Wu, T. and Chang, G. (2009) Leading Causes of Death from Injury and Poisoning by Age, Sex and Urban/Rural Areas in Tianjin, China 1999-2006. Injury, 41, 767-772.

[15] Boland, M., Staines, A., Fitzpatrick, P. and Scallan, E. (2005) Urban-Rural Variation in Mortality and Hospital Admission Rates for Unintentional Injury in Ireland. Injury Prevention, 11, 38-42. http://dx.doi.org/10.1136/ip.2004.005371

[16] Ostry, A.S. (2009) The Mortality Gap between Urban and Rural Canadians: A Gendered Analysis. Rural Remote Health, 9, Article No. 1286.

[17] Moshiro, C., Mswia, R., Alberti, K.G., Whiting, D.R. and Unwin, N. (2001) The Importance of Injury as a Cause of Death in Sub-Saharan Africa: Results of a Community-Based Study in Tanzania. Public Health, 115, 96-102. http://dx.doi.org/10.1016/s0033-3506(01)00426-7

[18] Mitchell, R.J. and Chong, S. (2010) Comparison of Injury-Related Hospitalised Morbidity and Mortality in Urban and Rural Areas in Australia. Rural Remote Health, 10, Article No. 1326.

[19] Peek-Asa, C., Zwerling, C. and Stallones, L. (2004) Acute Traumatic Injuries in Rural Populations. American Journal of Public Health, 94, 1689-1693. http://dx.doi.org/10.2105/AJPH.94.10.1689

[20] Nantulya, V.M. and Michael, R. (2002) The Neglected Epidemic: Road Traffic Injuries in Developing Countries. BMJ, 324, 1139-1141. http://dx.doi.org/10.1136/bmj.324.7346.1139 